\title{
ASPECTOS HISTÓRICOS DA FORMAÇÃO DE PROFESSORES PRIMÁRIOS EM SANTARÉM NO SÉCULO XX: O LEGADO DAS ESCOLAS ÁLVARO ADOLFO DA SILVEIRA, SANTA CLARA E SÃO JOSÉ
}

\author{
Paula de Souza Ferreira \\ paulaufpa@hotmail.com \\ Solange Helena Ximenes-Rocha \\ solange.ximenes@gmail.com \\ Maria de Fátima Matos de Souza \\ fmatoz@gmail.com
}

\section{RESUMO}

Os primeiros registros da história da educação no município de Santarém datam dos anos finais do século XVIII, quando foi fundada a primeira escola primária masculina. No entanto, estes registros não estão acompanhados da história da formação de professores. Este trabalho pretende entender a formação de professores do município de Santarém no século $\mathrm{XX}$, a partir de pesquisa com fontes iconográficas e documentais relativas aos cursos normais implantados no Colégio Santa Clara, Escola São José e Colégio Álvaro Adolfo da Silveira. Como metodologia adotou-se a Pesquisa Documental com análise dos seguintes documentos: resoluções, portarias, planos curriculares, matrizes curriculares, atas de formatura, decretos, pareceres. Os dados indicam a forte presença da Igreja Católica e do Governo do Estado na implantação de instituições educacionais em Santarém, todavia a participação do estado intensificou-se após a segunda metade do século XX quando observou-se maior carência de pessoal qualificado para atuar nas escolas da região.

Palavras-chave: Formação docente; história da educação; história das instituições escolares

\section{HISTORICAL ASPECTS OF PRIMARY TEACHER TRAINING IN SANTARÉM IN THE TWENTIETH CENTURY: THE LEGACY OF SCHOOLS ALVARO ADOLFO DA SILVEIRA, SANTA CLARA E SÃO JOSÉ}

\begin{abstract}
The first records of the history of education in the city of Santarém dating back to the final years of the XVIII century when it was founded the first male primary school. However, these records are not following by the history of teacher education. This article aims to understand the teachers education in Santarém in the XX century, from iconographic research and documentary about to the courses implanted in Santa Clara College, St. Joseph School and College Álvaro Adolfo da Silveira. The methodology was adopted documentary research with to analyze the following documents: dictum, ordinances, plan, curriculum, graduation record, decrees, statute. The data indicate the strong presence of the Catholic Church and the State Government in the implementation of educational institutions in Santarem, however the participation of the state intensified after the second half of the XX century when there was a greater shortage of qualified staff to work in schools the region. Keywords: Teacher education; history of education; history of educational institutions
\end{abstract}




\section{Introdução}

A questão da formação de professores é complexa e no Brasil foi enfrentada tardiamente. Mesmo que desde o período jesuítico houvesse ensaios de preparação de professores para o exercício do magistério, tal demanda foi percebida pelo governo após a independência do país a partir do acesso das camadas menos favorecidas à escola. As primeiras iniciativas de formação ficaram a cargo dos próprios docentes que deveriam financiar os cursos de qualificação recomendados pelo poder público.

Nos diferentes estados brasileiros a condução das orientações de formação de professores deu-se de maneira semelhante, influenciada principalmente pelos modelos europeus. Tal orientação baseou-se, prioritariamente, na oferta de cursos normais de preparação de professores para as primeiras séries.

Ao resgatar a história da formação de professores no Brasil observa-se uma lacuna nos escritos sobre a região norte. Quando se aprofunda a análise dos registros da região, estes estão restritos às capitais, como é o caso do Pará. Há poucos estudos sobre Santarém, por exemplo, uma cidade de significativa importância política e econômica no estado.

Os primeiros registros de educação no município de Santarém datam dos anos finais do século XVIII, quando é fundada a primeira escola primária masculina. Somente após 49 anos de existência é criada a primeira escola primária feminina, fundada em 1849 (COLARES, 2005). Na segunda metade daquele século surgiram várias escolas que por carência de professores e alunos fecharam em pouco tempo. Colares (2005) destaca que no período de 1883 a 1891 o município ficou sem escolas.

Com o desenvolvimento econômico impulsionado pela extração da borracha na Amazônia a educação formal é retomada em 1891 por meio de convênio com o Governo do Estado o qual instalou o Instituto Santareno que funcionou até 1894 e onde, no ano seguinte, começou a funcionar o Lyceu Santareno. Em 1900 foi criado pelo Governo do Estado do Pará o Grupo Escolar de Santarém, hoje denominado Escola Estadual Frei Ambrósio, que é a escola mais antiga do município.

As referências indicam a existência de informações quanto a educação escolar em Santarém, todavia, este registro não está acompanhado da história da formação de professores uma vez que se acredita que a expansão do atendimento escolar foi seguido da expansão da formação docente, ou deveria ser.

Este trabalho, desenvolvido pelo Grupo de Estudos e Pesquisas Formação de Professores na Amazônia - FORMAZON, tem como cerne levantar aspectos históricos sobre a formação de professores do município de Santarém no século XX, a partir de fontes históricas dos cursos normais implantados em escolas públicas e privadas do município.

Como metodologia adotou-se a pesquisa documental a qual proporciona resgatar e extrair informações que de acordo com Almeida, Guindani e Sá-Silva (2009, p.02) "possibilita ampliar o entendimento de objetos cuja compreensão necessita de contextualização histórica e sociocultural".

As pesquisas com fontes históricas valorizam e "se alimentam" do acervo histórico das instituições escolares. Nesse sentido, utilizamos para análise os seguintes documentos: resoluções, portarias, planos curriculares, matrizes curriculares, atas de formatura, decretos, pareceres. Desse modo acreditamos que a importância desse estudo reside na necessidade do resgate dos dados que indiquem a história da formação docente em Santarém, a partir do levantamento de fontes primárias e secundárias dos cursos normais de formação de professores.

As fontes para a pesquisa foram levantadas em três escolas localizadas no município de Santarém-Pará, quais sejam: Colégio Santa Clara, a Escola Conveniada de Ensino 
Fundamental e Médio São José e o Colégio Estadual de Ensino Médio Álvaro Adolfo da Silveira.

O Colégio Santa Clara e a Escola São José têm como mantenedora a Congregação das Irmãs Missionárias da Imaculada Conceição, todavia guardam particularidades. O Colégio Santa Clara é privado e está localizado na área central da cidade, já a Escola São José está localizada na área rural e além de ser mantida pela Congregação possui convênio com a Secretaria Estadual de Educação. O Colégio Álvaro Adolfo é mantido pelo Poder Público, por meio da Secretaria Estadual de Educação e também está localizado na área central da cidade.

Para este artigo, a apresentação da pesquisa está dividida em três momentos: primeiro faremos uma breve contextualização sobre a trajetória histórica dos cursos de formação docente no Brasil; na segunda parte discutiremos sobre a implantação dos cursos de formação docente no interior do Estado do Pará e finalizaremos a discussão refletindo sobre a carência de professores para trabalhar nas instituições educacionais instaladas no município de Santarém.

\section{Aspectos históricos da formação de professores no Brasil}

Ao analisar história da educação brasileira vamos perceber que as mudanças nas políticas educacionais se relacionam com as transformações ocorridas no processo econômico do país. Um exemplo disso pode ser percebido na desvalorização ocorrida na educação pública até o final da década de 1920. Até esse período, a oferta educacional se restringia basicamente ao ensino elementar, o qual era frequentado por filhos de trabalhadores rurais que não demonstravam muito interesse nos conhecimentos por ela ensinados, uma vez que a base da economia brasileira era agrária, e a maior parte da população estava concentrada na área rural. Essa realidade fazia com que a escola despertasse pouco interesse tanto para o Poder Público, como para a própria população, visto que:

[...] se a população se concentrava na zona rural e as técnicas de cultivo não exigiam nenhuma preparação, nem mesmo a alfabetização, está claro que para essa população camponesa, a escola não tinha qualquer interesse. Enquanto as classes médias e operárias urbanas procuravam a escola, porque dela precisavam para, de um lado, ascender na escala social e, de outro, obter um mínimo de condições para consecução de emprego nas poucas fábricas, para a grande massa composta de populações trabalhadoras da zona rural, a escola não oferecia qualquer motivação [...]. (ROMANELLI, 2002, p.45)

Se a educação pública ofertada não era prioridade para os governantes e era pouco interessante para os alunos, em função da forma como os currículos de ensino se estruturavam, podemos inferir que a formação de professores, para a educação elementar pública até esse período também se apresentava de forma precária, segundo Saviani (2009), a formação de professores só passa a ser motivo de preocupação a partir do fim do império, com os debates sobre a abertura e a organização da instrução popular.

A primeira tentativa de formação de professores no Brasil se dá a partir de $1834 \mathrm{com}$ a criação das Escolas Normais, "após a reforma constitucional de 12/08/1834" (TANURI, 2000, p.63), que conferia às Províncias a responsabilidade em administrá-las e fazê-las funcionar. Ainda segundo Tanuri: 
A primeira escola normal brasileira foi criada na Província do Rio de Janeiro, pela Lei $\mathrm{n}^{\circ} 10$ de 1835 , que determinava: "Haverá na capital da Província uma escola normal para nela se habilitarem as pessoas que se destinarem ao magistério da instrução primária e os professores atualmente existentes que não tiverem adquirido necessária instrução nas escolas de ensino mútuo, na conformidade da Lei de 15/10/1827” (2000, p.64).

Como podemos verificar, até esse período não havia uma preocupação com a formação de professores, portanto a criação das Escolas Normais se destinava a essa finalidade. A primeira escola normal foi criada no Rio de Janeiro, e posteriormente em outras províncias como Minas Gerais, Bahia, São Paulo, Pernambuco, Piauí, Alagoas, Rio Grande do Sul, Pará, Sergipe, Amazonas. Essa escola deveria dar conta de formar os futuros professores ou qualificar os que já estavam exercendo a função de forma deficitária nas escolas primárias, portanto, essa formação específica seria para qualifica-los ao exercício da docência. A esse respeito Saviani (2009) afirma que:

Visando à preparação de professores para as escolas primárias, as Escolas Normais preconizavam uma formação específica. Logo, deveriam guiar-se pelas coordenadas pedagógico-didáticas. No entanto, contrariamente a essa expectativa, predominou nelas a preocupação com o domínio dos conhecimentos a serem transmitidos nas escolas de primeiras letras. Portanto, o que se pressupunha era que os professores deveriam ter domínio daqueles conteúdos que lhes caberia transmitir às crianças, desconsiderando-se o preparo didático-pedagógico (SAVIANI, 2009, p.144).

O currículo das Escolas Normais contemplava conhecimentos sobre ler e escrever pelo método lancasteriano, além das quatro operações fundamentais para a matemática e proporções, a língua nacional, elementos de geografia, além de princípios de moral cristã.

As condições de oferta desse curso nas Escolas Normais, que deveria ser um diferencial na formação dos professores primários foi alvo de muitas críticas em função da mesma não possuir estrutura de pessoal, curricular e de infraestrutura física adequada para atingir o objetivo da formação desejada pelo sistema de ensino. A esse respeito Tanuri (2000) se posiciona dizendo que:

A organização didática do curso era extremamente simples, apresentado via de regra, um ou dois professores para toas as disciplinas e um curso de dois anos, o que se ampliou ligeiramente até o final do Império. O currículo era bastante rudimentar, não ultrapassando o nível e o conteúdo dos estudos primários, acrescido de rudimentar formação pedagógica, esta limitada a uma única disciplina (Pedagogia ou Métodos de Ensino) e de caráter essencialmente prescritivo. A infra-estrutura disponível, tanto no que se refere ao prédio, como a instalação e equipamento, é objeto de constantes críticas nos documentos da época (TANURI, 2000, p.65).

Diante do contexto em que as Escolas Normais foram implantadas e o fato terem ficado abandonadas em algumas províncias, as quais não investiram financeiramente para estrutura-las e adequá-las para efetivamente formar professores, fez com que as mesmas ficassem desacreditadas, como analisa Tanuri:

O insucesso das primeiras escolas normais e os parcos resultados por elas produzidos granjearam-lhes tal desprestígio que alguns presidentes de 
Províncias e inspetores de Instrução chegaram a rejeitá-las como instrumento para qualificação de pessoal docente, indicando como mais econômico e mais aconselhável o sistema de inspiração austríaca e holandesa dos "professores adjuntos" (2000, p.65).

É importante lembrar que dada o fracasso das Escolas Normais, algumas mecanismos para trazer professores com qualificação para as escolas primárias foram buscados, se consideramos que "[...] várias províncias lançaram mão de instrumento economicamente mais interessante para recrutamento de docentes: os exames ou concursos" (TANURI 2000, p.65). Esse mecanismo não teve muito sucesso, porque apesar dos governos provinciais fazerem seleção para escolher os docentes, a procura era tímida, o que pode se dever ao fato de já haver sinais da desvalorização do curso e da profissão.

Depois de algumas dificuldades, entendidas como administrativas, as Escolas Normais passam por reformas, com o objetivo de que atendessem a demanda de qualificação de professores que o país necessitava. Umas das reformas importantes que podemos destacar se deu na Escola Normal de São Paulo, ocorrida em 12 de março de 1890. A referida escola passou por mudança significativa nos conteúdos curriculares e nas atividades práticas do curso, além de ter possibilitado avanços no que se refere ao desenvolvimento da profissão. De acordo com Saviani:

A reforma foi marcada por dois vetores: enriquecimento dos conteúdos dos conteúdos curriculares anteriores e ênfase nos exercícios práticos de ensino, cuja marca característica foi a criação da escola-modelo anexa à Escola Normal - na verdade a principal inovação da reforma. Assumindo os custos de sua instalação e centralizando o preparo dos novos professores nos exercícios práticos, os reformadores estavam assumindo o entendimento de que, sem assegurar de forma deliberada e sistemática por meio da organização curricular a preparação pedagógico-didática, não se estaria, em sentido próprio, formando professores (2009, p.145).

A partir da reforma na Escola Normal paulista as demais escolas do país seguindo esse modelo também passaram por mudanças, cujo discurso para justificar tais reformas era de melhoria na qualidade do ensino ofertado em todas as escolas existentes no Brasil, assim como ir de encontro ao pensamento elitista da República.

Após esse período, a literatura aponta que mais cinco reformas entre 1990 e 1930 foram realizadas no ensino, porém as mesmas privilegiavam sempre o Ensino Secundário e o Ensino Superior e todas elas tinham por objetivo, segundo seus formuladores, melhorar a qualidade do ensino, porém, elas estavam voltadas a atender as exigências da elite dominante.

As políticas de formação docente nesse período, para atender a demanda da elite dominante voltavam os currículos mais para conteúdos e técnicas do que para uma formação integral do cidadão, como observado por Ranghetti (2008, p.07), quando afirma que "[...] a educação permaneceu elitista e excludente, favorável às oligarquias que estavam no poder [...] Desse modo, o currículo, formador de consciências, entre 1889 e 1930, pode ser classificado como classista e discriminatório[...]".

Através da Lei $\mathrm{n}^{\circ} 175$, de 8 de dezembro de 1920, as Escolas Normais passaram por mais uma reforma, dessa vez a reforma se centrou no currículo, os quais foram unificados, ou seja, passaram a ser trabalhados nas Escolas Normais currículos com padrões de ensino mais elevados. 
Em 19 de março de 1932, através do decreto de $n^{\circ} .3 .810$, as Escolas Normais passam por mais uma reforma, dessa vez através da mudança de currículo e de nomenclatura, passando de Escola Normal para Escola de Professores. Dessa forma, a Escola de Professores se preocupou com uma formação mais geral, porém essa formação geral se concentrou em ampliar o número de disciplinas a serem ofertadas e não na formação integral do professor, como era reivindicada pelos educadores. O currículo dessas "novas escolas" passou a ofertar as seguintes disciplinas, segundo Saviani:

1) biologia educacional; 2) sociologia educacional; 3) psicologia educacional; 4) história da educação; 5) introdução ao ensino, contemplando três aspectos: a) princípios e técnicas; b) matérias de ensino abrangendo cálculo, leitura e linguagem, literatura infantil, estudos sociais e ciências naturais; c) prática de ensino, realizada mediante observação, experimentação e participação, como suporte ao caráter prático do processo formativo, a escola de professores contava com uma estrutura de apoio que envolvia: a) jardim de infância, escola primária e escola secundária, que funcionavam como campo de experimentação, demonstração e prática de ensino; b) instituto de pesquisas educacionais; c) biblioteca central de educação; d) bibliotecas escolares; e) filmoteca f) museus escolares; g) radiodifusão (2009, p. 145 e 146).

Como podemos perceber acima, as mudanças ocorridas nessas escolas não foram apenas de nomenclatura e currículo, mas também administrativa, foi uma tentativa de dar uma organicidade as mesmas tanto no que concerne ao currículo, as práticas educacionais, estrutura física, etc. Essa mudança visava possibilitar aos alunos melhores condições de ensino-aprendizagem no decorrer do processo de formação.

Apesar da reforma realizada nas escolas de formação de professores, elas continuaram a ser alvo de críticas, porque a formação oferecida não atendia aos anseios dos professores. A partir da década de 1930, com o Manifesto dos Pioneiros da Educação Nova, deflagrado em março de 1932, se intensificam as denúncias sobre a precariedade dos cursos de formação docente, porque os professores que nelas ingressavam viam nessa formação um fim em si mesma, ou seja, a formação ofertada não possibilitava que galgassem um ingresso ao ensino superior, em função do currículo limitado do curso. Dessa forma,

Em março de 1932 o Manifesto dos Pioneiros da Educação Nova é divulgado, denunciando a precariedade da formação inicial docente, notadamente a do magistério primário, entendendo que os professores tinham formação nas escolas normais, sem perspectiva de acesso ao ensino superior (RANGHETTI, 2008, p.08).

Dada a crise na formação inicial dos professores, foi criado em 1934, pela Universidade de São Paulo, na Faculdade de Filosofia, Ciências e Letras, o Curso Superior de Formação Docente, denominado "Curso de Pedagogia". Esse curso visava dar uma formação mais elevada aos professores primários. A duração do bacharelado seria de três anos e a licenciatura seria complementada em mais um ano de didática, em um esquema que ficou conhecido como " $3+1$ ".

Segundo este padrão todas as instituições de ensino superior tiveram que adaptar os seus currículos básicos. Brzezinski (1996, p.44) afirma que "com essa configuração o bacharelado em Pedagogia percorria um caminho oposto aos demais bacharelados. Estudavam-se generalidades como conteúdo de base e superpunha-se o específico num curso à parte - o de didática da Pedagogia”. Com essa característica a matriz curricular do Curso 
de Pedagogia se preocupava, assim como a escola normal, apenas com uma formação prescritiva e alienada, como observa Ranghetti:

No currículo do primeiro curso de Pedagogia implantado no País os aspectos técnicos sobrepunham aos aspectos pedagógicos, sem contemplar a prática de ensino, configurando uma educação para a alienação. A formação do professor, mesmo em nível universitário, era tecida por um currículo prescrito, sem vida, no qual o poder se materializava na formação de consciências submissas à ordem estabelecidas como forma de conseguir ascensão social (2008. p.10).

A forma como o curso foi criado e estruturado demonstra não haver verdadeiramente uma definição de seu papel, logo é um curso que nasce com uma crise de identidade. Essa situação faz com o que a profissionalização oferecida no curso seja amplamente questionada, ao ponto de nos discursos contrários pedirem a extinção do curso, dado seu caráter generalista.

Com a homologação da Lei de Diretrizes e Bases de 1961 (4.024/61), o currículo do Curso de Pedagogia em 1962, sofre as primeiras e pequenas alterações após sua criação. Assim, tais alterações, discutidas no Parecer do Conselho Federal de Educação - CFE, de $\mathrm{n}^{\mathrm{o}}$. 251, cujo relator foi o Conselheiro Valnir Chagas, estão restritas à fixação do currículo mínimo e à duração do curso de Pedagogia. O Conselheiro explicita a fragilidade do Curso de Pedagogia conforme destaca Silva (1999, p. 36-37),

[...] logo de início, à controvérsia existente a respeito da manutenção ou extinção do curso. Explica que a idéia da extinção provinha da acusação de que faltava ao curso conteúdo próprio, na medida em que a formação do professor primário deveria se dar ao nível superior e a de técnicos em Educação em estudos posteriores ao da graduação [...]. A previsão do autor do parecer é que, antes de 1970, nas regiões mais desenvolvidas, esse curso teria que ser redefinido e que, provavelmente, nele se apoiariam os primeiros ensaios de formação superior do professor primário.

O Parecer/CFE 251/62 previa que o Curso de Pedagogia se destinava à formação do "técnico em Educação" e do professor de disciplinas pedagógicas do Curso Normal, por meio do bacharelado e da licenciatura, respectivamente.

Enquanto o curso superior de formação de professores para as Escolas Normais tenta encontrar sua identidade, vem uma nova reforma no ensino fazer alteração na Escola Normal, como resultado das divergências e desvalorização que a profissão docente vinha sofrendo perante a sociedade. Com a aprovação da Lei Orgânica do Ensino Normal n ${ }^{\circ} 8.530$ de 2 de janeiro de 1946, há uma mudança no currículo do curso, ele passou a ser denominado de Habilitação Específica para o Magistério, ou seja, uma nova fase na política de formação de professores no Brasil se inicia.

[...] a Lei Orgânica do Ensino Normal (1946) estabeleceu a existência de dois níveis diferentes de escolas de formação, São Paulo continuou com seu ensino de tipo único, o que só foi alcançado pela maioria dos estados com a Lei 5.692/72 (sic). Com a unificação, já em 1920 o Estado passou a contar com dez escolas normais públicas, o que foi de fundamental importância para satisfazer às exigências apresentadas pela expansão do ensino primário da época. Evidencia-se assim a tendência de progressiva elevação do nível do curso normal dentro da estrutura vertical do sistema de ensino (TANURI, 2000, p.69). 

de que:

A esse respeito, Saviani (2009) aprofunda a análise, chamando a atenção para o fato

Na nova estrutura, o curso normal, em simetria com os demais cursos de nível secundário, foi dividido em dois ciclos: o primeiro correspondia ao ciclo ginasial do curso secundário e tinha duração de quatro anos. Seu objetivo era formar regentes do ensino primário e funcionaria em Escolas Normais regionais. O segundo ciclo, com duração de três anos, correspondia ao ciclo colegial do curso secundário. Seu objetivo era formar professores do ensino primário e funcionaria em Escolas Normais e nos institutos de educação (SAVIANI, 2009, p.146).

Com essas mudanças o governo justificava a alteração na política de formação de professores, porém, tais modificações não foram suficientes para melhorar a qualidade do ensino primário, haja vista que ainda existia um número elevado de evasão e reprovação.

Nos anos 1950 nota-se no âmbito das Instituições de Ensino, ainda influenciadas pelas ideias da Escola Nova, certa preocupação no que diz respeito as metodologias de ensino. Tanuri (2000) aponta que:

$\mathrm{Na}$ euforia desenvolvimentista dos anos 50, as tentativas de "modernização" do ensino, que ocorriam na escola média e na superior, atingem também o ensino primário e a formação de seus professores. Assim, merece referência a atuação desenvolvida pelo Programa de Assistência Brasileiro Americana ao Ensino Elementar (PABAEE), de 1957 a 1965-resultante de acordo entre o MEC/INEP e a USAID-, cujo objetivo prioritário foi inicialmente a instrução de professores das escolas normais, no âmbito das metodologias de ensino, e com base na psicologia, objetivo esse que se estendeu também ao campo da supervisão e do currículo, com vistas a atingir ocupantes de postos de liderança, que pudessem ter uma ação multiplicadora de maior abrangência (TANURI, 2000, p.78).

Esses aspectos observados por Tanuri (2000) fazem crer que os pensamentos idealistas dos Cursos Normais foram ampliados com a promulgação da Lei de Diretrizes e Bases da Educação Nacional de nº 4.024/61. Essa Lei veio se preocupar com as mudanças curriculares dos cursos de formação de professores no entanto não apresentou soluções inovadoras mantendo a organização anterior.

As reformas estaduais das escolas normais, com vistas a ajustá-las à nova Lei, limitaram-se principalmente a alterações curriculares. A maioria dos estados conservou o sistema dual, com escolas normais de nível ginasial, com quatro séries no mínimo, e as de nível colegial, com três séries no mínimo, certamente em face da insuficiente quantidade de candidatos qualificados para a docência no ensino primário (TANURI, 2000, p.78).

Após a Lei de Diretrizes e Bases da Educação Nacional $n^{\circ}$ 4.024/61 observa-se impulso maior em modernizar as Escolas Normais. Tanuri (2000) esclarece que:

Na conjuntura histórica pós-64, as preocupações da literatura educacional, dos conteúdos curriculares e dos treinamentos dos professores deslocamse principalmente para os aspectos internos da escola, para os "meios" destinados a "modernizar" a prática docente, para a "operacionalização" dos objetivos - instrucionais e comportamentais -, para o "planejamento, e 
coordenação e o controle" das atividades, para os "métodos e técnicas" de avaliação, para a utilização de novas tecnologias de ensino, então referentes sobretudo a "eficiente e produtiva", ou seja, de torná-la operacional com vistas à preparação para o trabalho, para o desenvolvimento econômico do país, para segurança nacional (TANURI, 2000, p.79).

Deve-se observar que apesar das mudanças o debate em torno da formação de professores para o ensino primário não se encerra, pelo contrário as divergências em relação às Escolas Normais, mesmo com a modernização dos cursos de formação de professores se acentuam, conforme observa Tanuri (2000). Diante da crise estabelecida em torno das Escolas Normais, as mesmas deixaram de existir mediante a aprovação da Reforma de ensino de $1^{\circ}$ e $2^{\circ}$ graus n ${ }^{\circ} 5.692 / 71$, que de acordo com Saviani (2009, p.147) "modificou os ensinos primário e médio, alterando sua denominação respectivamente para primeiro grau e segundo grau".

Tanuri (2000) sobre o Curso Normal acredita que:

A Lei 5.692/71, que estabeleceu diretrizes e bases para o primeiro e o segundo graus, contemplou a escola normal e, no bojo da profissionalização obrigatória adotada para o segundo grau, transformouse numa das habilitações desse nível de ensino, abolindo de vez a profissionalização antes ministrada em escola de nível ginasial. Assim, a já tradicional escola normal perdia o status de "escola" e, mesmo, de "curso", diluindo-se numa das muitas habilitações profissionais do ensino de segundo grau, a chamada Habilitação Específica para o Magistério (HEM). Desapareciam os Institutos de Educação e a formação de especialistas e professores para o curso normal passou a ser feita exclusivamente nos cursos de Pedagogia (TANURI, 2000, p.80).

Os Cursos Normais foram substituídos pelos Cursos de Habilitação Específica para o Magistério, o qual tinha por objetivo formar professores para o primeiro grau. Esse curso foi organizado em duas modalidades básicas, segundo Saviani (2009, p.147): "uma com duração de três anos (2.200 horas), que habilitaria a lecionar até a quarta série; e outra com duração de quatro anos (2.900 horas), habilitando ao magistério até a $6^{\mathrm{a}}$ série do $1^{\circ}$ grau".

O Curso Normal de Formação de Professores e os Cursos Secundários foram abolidos mediante a Reforma $\mathrm{n}^{\circ} 5.692 / 71$ e em substituição foi criado o ensino de $1^{\circ}$ e $2^{\circ}$ graus. Essa lei estabeleceu diretrizes para a organização do ensino. De acordo com a Lei, o Curso Normal dá lugar à Habilitação Específica para o Magistério, o qual passou a adotar um esquema integrado, flexível e progressivo de formação de professores, conforme pode ser observado a seguir:

Art. 29. A formação de professores e especialistas para o ensino de $1^{\circ}$ e $2^{\circ}$ graus será feita em níveis que se elevem progressivamente, ajustando-se às diferenças culturais de cada região do País, e com orientação que atenda aos objetivos específicos de cada grau, às características das disciplinas, áreas de estudo ou atividades e às fases de desenvolvimento dos educandos (Lei $\left.{ }^{\circ} 5.692 / 71\right)$.

Ao analisar o currículo do Curso de Magistério Tanuri (2000, p.81) chama a atenção para o fato de que o mesmo "[...] deveria apresentar um núcleo comum de formação geral, obrigatório em âmbito nacional - composto de disciplinas da área de comunicação e 
expressão, estudos sociais e ciências - e uma parte de formação especial". A autora observa ainda que o currículo estava baseado nos conhecimentos da biologia, psicologia, sociologia, história e filosofia da educação, além dos conhecimentos da didática e prática de ensino. Entretanto, esse currículo acabou não sendo considerado devido à fragmentação do curso, pois surge a ideia de separar o curso em várias habilitações específicas para uma determinada série, como explicado pela autora:

[...] previa-se a possibilidade do fracionamento do curso em habilitações específicas, em três ou quatro séries, ou seja, a habilitação para o magistério em escolas maternais e jardins-de-infância; em $1^{\mathrm{a}}$ e $2^{\mathrm{a}}$ séries; em $3^{\mathrm{a}}$ e $4^{\mathrm{a}}$ séries, em $5^{\mathrm{a}}$ e $6^{\mathrm{a}}$, entre outras, com conteúdos correspondentes a cada uma delas (TANURI, 2000, p.81).

Assim como as demais políticas de formação de professores para as séries iniciais, as críticas não cessaram com a reforma. As críticas ao curso eram de toda ordem, tais como:

[...] dicotomia entre teoria e prática, entre conteúdo e método, entre núcleo comum e parte profissionalizante; à inexistência de articulação entre o processo de formação e a realidade do ensino de $1^{\circ}$ grau; ao desprestígio social do curso e à sua inconsistência em matéria de conteúdo; à inadequação dos docentes ao curso, em termos de formação, tendo em vista a inexperiência de muitos deles o ensino de $1^{\circ}$ grau e a necessidade de assumirem várias disciplinas; à insuficiência e à inadequação dos livros didáticos; aos problemas pertinentes à realização do estágio de Prática de Ensino (TANURI, 2000, p.82).

Diante dessa realidade o curso sofreu penalidades quando as matrículas diminuíram consideravelmente, além de questões que desprivilegiavam a profissão desde o início de sua história: desvalorização da profissão de professor. Para melhorar a situação da formação docente, foram criados os Centros de Formação e Aperfeiçoamento do Magistério (CEFAM), cujo objetivo era "redimensionar as escolas normais, dotá-las de condições adequadas à formação de profissionais com competência técnica e política e ampliar-lhes as funções de modo a torná-las um centro de formação inicial e continuada", (CAVALCANTE, 1994 apud TANURI, 2000, p.82).

Com essa nova proposta de curso para formação docente Vicentini e Lugli (2009, p.51) ressaltam que "tal projeto visava a fortalecer as condições das escolas de formação de professores, para que estas tivessem condições de preparar adequadamente novos docentes em nível médio, que atuariam no ensino pré-escolar e nas séries iniciais". Dessa forma o currículo do Curso de Formação e Aperfeiçoamento do Magistério possuía uma carga horária extensa, realizada em período integral, durante 4 anos. Ainda sobre o currículo do curso Vicentini e Lugli (2009) afirmam que:

[...] A carga horária semanal distribuía-se em 30 horas-aula das disciplinas da Habilitação Específica para o Magistério e mais 18 horas-aula de atividades de enriquecimento curricular, que funcionavam para a complementação do currículo mínimo: aulas de reforço e o desenvolvimento de projetos e atividades diversificadas para o enriquecimento dos conteúdos das disciplinas. Além disso, o currículo da Habilitação ao Magistério foi reorganizado, de modo a obter um maior equilíbrio entre a parte comum e a diversificada (VICENTINI e LUGLI, 2009 p.51/52). 
Ainda que pudessem ser identificados os esforços do governo para com a qualificação docente no país, considerava-se insuficiente, pois nas duas últimas décadas o investimento para os cursos de formação docente pautou-se na criação do Curso Magistério e no reforço a este com a criação dos Centros de Formação e Aperfeiçoamento do Magistério (CEFAM).

Na última década do século XX é promulgada a nova Lei de Diretrizes e Bases da Educação n ${ }^{\circ} 9.394$ de 20 de dezembro de 1996, que deu atenção especial à formação docente. Essa nova LDB extinguiu os cursos de magistérios e através do seu Artigo 62 definiu que:

A formação de docentes para atuar na educação básica far-se-á em nível
superior, em curso de licenciatura, de graduação plena, em universidades
e institutos superiores de educação, admitida, como formação mínima para
o exercício do magistério na educação infantil e nas quatro primeiras séries
do ensino fundamental, a oferecida em nível médio, na modalidade Normal
(Lei no ${ }^{\circ} 9.394$ de 20 de Dezembro de 1996).

Com a aprovação da LDB 9.394/96 e a extinção dos cursos de magistério, a política de formação de professores na atualidade se dá através dos cursos de Licenciatura. Para atender essa nova fase de formação os cursos de licenciatura foram reformulados. O próprio governo federal criou uma política nacional de formação de professores em 2009, chamada PARFOR, o qual tem por objetivo qualificar em nível superior os professores leigos e habilitar os professores, sejam os que não possuem nível superior ou os que atuam em área diferente de sua formação.

O Estado do Pará, por ser considerado o maior Estado da região Norte, acompanhou todo esse movimento de formação de professores. Sendo que a primeira instituição de formação de professoras data do século XIX, Instituto de Educação do Pará (IEP) que nasceu de forma vaga e incipiente, com a inclusão, em 1841, de uma aula de ensino normal, no currículo do Liceu Paraense e somente em 1871, o poder público encarou de fato e de direito a questão do preparo da formação do professor para a escola primária, na Província paraense, criando a Escola Normal, Lei 669 de 13 de abril de 1871. É uma das instituições escolares mais antigas do Brasil, por ela passaram muitas gerações de paraense, entre elas suas professoras e professores, entretanto quando se perscruta a história de formação de professoras no Brasil, não há registro de sua trajetória em meio as outras.

O município de Santarém, considerado o segundo maior município do Estado, até hoje sofre com os insucessos das políticas de formação de professores vivenciadas no decorrer da história das instituições de ensino aqui implantadas. A falta de professores qualificados para o exercício da docência, de acordo com o estabelecido em lei perdura até os dias atuais, se considerarmos que ainda temos muitos professores sem formação em nível superior atuando nas escolas, principalmente nas localizadas no campo.

\section{A IMPLEMENTAÇÃO DOS CURSOS DE FORMAÇÃO DOCENTE EM SANTARÉM-PARÁ}

Esta sessão do artigo aborda o processo de escolarização no Município de Santarém, no qual se enfatiza o período inicial da oferta de educação formal, assim como destaca o momento de expansão do sistema educacional ocorrido no século XX, a partir do desenvolvimento comercial, aumento da população e da construção de prédios escolares. Destaca ainda as demandas de ampliação da oferta educacional e a carência de professores 
qualificados para o exercício do magistério, assim como destaca as iniciativas governamentais para solucionar a carência de professores no interior do Estado do Pará.

\section{O Desenvolvimento Econômico e o Processo de Escolarização no Município de Santarém/Pa}

Os primórdios da Educação Formal no município de Santarém datam do final do século XVIII, quando foi criada a primeira escola voltada para educação de meninos. Segundo (COLARES 2005, p.35) a data de fundação dessa escola é de meados de 1799 ou 1800. É importante ressaltar que a referida instituição não contemplava cuidados de ordem religiosa alguma, pelo contrário, estava sob cuidados públicos. De acordo com o autor:

A escola masculina, primária, era pública ao passo que as aulas de gramática, francês e latim eram particulares. A carência de professores, assim como a tentativa de resolver o problema via decreto, reflete ainda um período em que a organização social e o desenvolvimento econômico do povoado era insuficiente para que a educação pudesse representar uma necessidade e, por conseguinte, o poder público adotasse medidas mais apropriadas e eficientes conforme a situação exigida (COLARES, 2005, p.35).

De acordo com Fonseca (1996, p.42 e 43) o número aproximado de habitantes na cidade era de 2 mil, somados àqueles que moravam em fazendas e em comunidades do interior a quantidade de habitantes chegava a 4 mil.

Somente após 49 anos de fundação da primeira escola foi criada a primeira escola feminina, instituída pela Lei Provincial n ${ }^{\circ}$ 157, de 20 de novembro de 1849, mas é importante ressaltar que os profissionais para atuarem nessas escolas eram oriundos da capital da província.

Por volta de 1850, Santarém tornou-se "um importante entreposto comercial, que contava com mais de meia centena de embarcações" (COLARES 2005, p.36). Observa-se que o número de habitantes cresceu consideravelmente para cerca de 7 mil, o que estimulou a atenção do então presidente da província, o Sr. Henrique de Beaurepaire Rohan e o fez publicar a Lei $\mathrm{n}^{\circ} 288$ de 20 de setembro de 1856, na qual incentivava a instalação de novas escolas para atender a demanda já existente no município.

É importante lembrar que no período de 1883 a 1891 os registros de Colares (2005, p.41) apontam que Santarém havia ficado sem nenhuma instituição de ensino. Por volta de 1891 foi criado o Instituto Santareno. A partir de 1895 surge um novo momento para o contexto educacional do município, isso se deve à instalação do "Lyceu Santareno", fundado no dia 11 de fevereiro do ano referido. Essa instituição de ensino pode ser considerada como particular, pois os alunos pagavam em réis, moeda da época, "15\$000 a cada ano, para qualquer modalidade; $6 \$ 000$ por uma aula avulsa; $10 \$ 000$ por duas, $12 \$ 000$ por três e $5 \$ 000$ pelo curso primário" (COLARES 2005, p.45).

No século XX a educação no município passou por uma fase promissora devido a criação de várias instituições de ensino. Em 3 de maio de 1900 foi fundado o Grupo Escolar de Santarém, hoje Escola Frei Ambrósio. A partir de então são criados novos estabelecimentos educacionais. Face ao exposto podemos identificar uma política de fixação das instituições de ensino no município tendo em vista o crescimento populacional, o apoio do Estado e a força política da Igreja Católica na cidade. De acordo com Colares (2005): 
A Igreja Católica, inegavelmente, liderou a difusão do ensino em Santarém, especialmente a partir do início do século XX, quando também o Estado passou a ter uma participação mais efetiva nesse processo, haja vista o número de estabelecimentos públicos com que o município passou a contar. Por exemplo, em 1930, havia 32 escolas públicas (13 estaduais e 19 municipais) (COLARES, 2005, p.57)

\section{As Demandas de Ampliação da Oferta Educacional e a Carência de Professores Qualificados}

A partir das décadas de 1960 e 1970 houve aumento no atendimento público educacional. Na década de 60 ofertava-se as modalidades de ensino Primário e Ginasial com 1.868 alunos matriculados, dentre uma população urbana de 24.498 habitantes. Na década de 70 houve aumento significativo nas matriculas nos Cursos Primário e Ginasial que foi de 9.601, para uma população de 51.009 habitantes da área urbana.

Face ao aumento significativo na demanda por vagas, acentuou-se a carência de professores. As escolas existentes - Colégio Santa Clara e Escola São José - não eram suficientes para atender à demanda de formação de pessoal qualificado para o exercício do magistério, principalmente para o ensino médio.

Somente no ano de 1962 é fundado o Colégio Álvaro Adolfo da Silveira que passou a ofertar outros Cursos de Formação Docente, quais sejam: Curso Ginasial, Pedagógico, Colegial Normal e o Curso com Habilitação em Magistério. Tal feito é significativo no contexto territorial da região, considerando-se as grandes distâncias amazônicas e as dificuldades de acesso, uma vez que o Colégio Álvaro Adolfo passou a atender gratuitamente as demandas de profissionalização e evitou o deslocamento dos interessados para a capital do estado em busca de qualificação.

\section{A trajetória histórica das instituições educacionais pesquisadas}

\section{Colégio Santa Clara}

A fundação do Colégio Santa Clara aconteceu em 11 de agosto de 1913 e teve como mentores Madre Imaculada de Jesus Tombrock e Dom Amando Bahlman, segundo fontes escritas da Instituição "o Colégio foi fundado em decorrência da necessidade de escolas para atender principalmente às crianças pobres e órfãs e também pelo forte desejo de Madre Imaculada de se dedicar à causa educativa" (O Colégio Santa Clara-Histórico).

Em 9 de dezembro de 1916 foi ofertado o primeiro Curso do Colégio, tratava-se do Curso Primário. Após vinte e três anos foi oferecido o Curso Normal de $1^{\circ}$ ciclo, cujo objetivo era "o atendimento às jovens pobres e órfãs que não podiam se deslocar para a capital a fim de completar os seus estudos, como também o preparo de professores que pudessem servir, [...] às escolas do interior" (O Colégio Santa Clara Histórico).

É registrado no documento "O Colégio Santa Clara-Histórico" que no ano de 1946 começa a funcionar o Curso Ginasial de $1^{\circ}$ ciclo, outorgado pela Portaria $n^{\circ} 700$ de 19 de dezembro de 1946, mas este fato se deve à persistência da Congregação em relevar as muitas respostas negativas aos telegramas enviados ao Ministério da Educação. No mesmo ano foi publicada a Lei Orgânica do Ensino Normal nº 8.530 de 02 de Janeiro de 1946, cuja proposta era de ampliar o Curso Normal para sete anos, os quais foram divididos em dois ciclos (SAVIANI, 2009, p.146). Em 1951 o Colégio Santa Clara implantou o Curso Normal de $2^{\circ}$ ciclo. 
Em 1976 o Colégio passou a ofertar os cursos com as habilitações em nível de $2^{\circ}$ grau em Comércio, Administração e Magistério. Até 30 de março de 1995 o Colégio funcionou com os Cursos Maternal, Jardim, Alfabetização $1^{\circ}$ Grau Menor ( $1^{\mathrm{a}}$ a $4^{\mathrm{a}}$ séries), $1^{\mathrm{o}}$ Grau Maior ( $5^{\mathrm{a}}$ a $8^{\mathrm{a}}$ séries), $2^{\circ}$ Grau Magistério, $2^{\circ}$ Grau Ciências Humanas e $2^{\circ}$ Grau Ciências Biológicas. Com as novas exigências da Lei 9.394/96 o Curso de $2^{\circ}$ Grau foi substituído pelo Ensino Médio.

\section{Escola São José}

A Escola Conveniada São José foi fundada em 10 de outubro de 1919, por Dom Amando e Madre Maria Imaculada de Jesus, fundadores da Congregação das Irmãs Missionárias da Imaculada Conceição. A fundação da Escola se deu após nove anos da fundação da Congregação no município de Santarém, e ainda, pode-se afirmar, que a criação de uma Escola na área rural de Santarém deu-se devido a ampliação das ações de evangelização, haja vista que a Congregação estava presente em muitos municípios do Estado do Pará, e até em outros países.

Durante o período que compreendeu o ano de 1919 até meados de 1952 a instituição passou por dificuldades, pois além de não possuir profissionais com formação mínima, a questão da infraestrutura deixava a desejar. É importante frisar que a sala de aula era localizada em anexo a residências das freiras.

No dia 20 de outubro de 1953 a Escola São José conseguiu registro de personalidade jurídica, através do reconhecimento $\mathrm{n}^{\circ} 6$ do Livro R-1 fls. 910, no Cartório de Registro: Títulos e Documentos de Santarém. Por meio desse registro jurídico a Escola conseguiu, através de parcerias, erguer sua infraestrutura. O novo prédio da instituição media 867,02 $\mathrm{m}^{2}$, com uma capacidade para 1.000 alunos. Em 26 de junho de 1956, pelo decreto estadual de $\mathrm{n}^{\mathrm{o}} 2.085$, é ofertado o primeiro Curso Formal de ensino primário. Em 04 de março de 1962 começa a funcionar o Curso Normal/Regional, que formava o professor para o Curso Primário.

Com a Resolução $n^{\circ}$ 178/84, a escola recebeu autorização do governo, e passou a funcionar com o ensino de $1^{\circ}$ grau $\left(1^{\mathrm{a}}\right.$ a $8^{\mathrm{a}}$ série $)$. Após oito anos é promulgada a Portaria $\mathrm{n}^{\mathrm{o}}$ 1.016/92 que autoriza a implantação do Curso via Sistema Modular, com Habilitação em Magistério, tendo a primeira turma formado 26 professoras em 19 de junho de 1995 e a última formado 19 professoras em 03 de fevereiro de 2001. O Curso de magistério, segundo fontes escritas por Irmã Terezinha, formou 117 professores para atuarem no campo. Em 1999 com a Portaria ${ }^{\circ} 129$ é implantado o ensino médio, extinguindo os Cursos de Formação de Professores.

\section{Colégio Álvaro Adolfo da Silveira}

O Colégio Álvaro Adolfo foi autorizado a funcionar pela Lei $\mathrm{n}^{\circ} 2.033$ de 31 de outubro de 1960. No entanto há duas versões sobre a história de fundação do referido Colégio. Na primeira a fundação do Colégio é datada de 30 de abril de 1962, autorizada pela portaria $n^{\circ} 661$ de 18 de abril de 1962. Na outra, os registros apontam que o início do funcionamento aconteceu em $1^{\circ}$ de maio do mesmo ano.

O que se sabe diante do impasse é que o ano de inauguração foi em 1962, e também houve grande satisfação da população municipal com a instalação do Colégio, pois ele "foi fundado para atender as necessidades prementes da Juventude Santarena, carente de recursos, mas ávida pelo estudo e saber" (Arquivo da Instituição).

O Colégio Álvaro Adolfo iniciou suas atividades na Escola Frei Ambrósio, pois ainda não tinha prédio para atender a demanda de alunos. Após quatro anos de espera o novo 
prédio, considerado o "mais belo e moderno prédio Educacional do interior do Estado", passou a funcionar nos três horários. A partir de então entende-se que começaria um novo momento para a história da educação no município, pois outros cursos gratuitos passaram a ser ofertados, quais sejam: Curso primário, Ginasial Secundário, Pedagógico e o Colegial Normal, algum tempo depois o Colégio passou a ofertar o Curso Científico (Arquivo da Instituição). A partir da Lei $n^{\circ}$ 5.692/71 a Escola passou a oferecer outros cursos, entre eles a Habilitação Técnica em Magistério.

Em 1985 registra-se a implantação do Curso de Estudos Adicionais, tendo como objetivo profissionalizar os concluintes do Curso de Magistério em áreas distintas como de Língua Portuguesa, Matemática, Ciências, História e Geografia. Até meados do ano de 2000 o Curso de Magistério funcionou normalmente no Colégio.

\section{Os cursos de formação de professores em Santarém no século XX}

O desenvolvimento econômico do município de Santarém teve impulso inicial no século XIX, quando se tornou rota comercial. A partir de então aumentou o número de habitantes e em consequência disto houve a necessidade de instalação de instituições de ensino para atender as demandas de escolarização emergentes. Tal iniciativa, liderada pelo Governo do Estado encontrou dificuldades, pois não havia pessoal qualificado.

Mesmo assim pode-se destacar a fundação do Colégio Santa Clara em 11 de agosto de 1913, pela Congregação das Irmãs Missionárias da Imaculada Conceição, localizado na área urbana da cidade. O referido colégio iniciou as suas atividades sem o aval do Governo Estadual, seu propósito era proporcionar uma educação que assistisse as dificuldades dos moradores do município, além de desenvolver atividades evangelizadoras da Igreja Católica.

A participação governamental neste processo deu-se no ano de 1939, quando o Colégio solicita ao governo assistência, no intuito de formalizar o seu funcionamento, assim como proporcionar formação de professores para atuação no município. A partir de então foi ofertado o primeiro curso, denominado de Curso Normal de $1^{\circ}$ ciclo. Antes desta data os dados permitem compreender que a oferta do Curso Primário acontecia com a participação de professores leigos.

Fundado em 10 de outubro de 1919, a Escola São José, também administrada pela Congregação das Irmãs Missionárias da Imaculada Conceição, ofertou capacitação docente, com professoras leigas até o ano de 1953. A participação das autoridades administrativas do Estado deu-se somente em 1956 quando é autorizada a implantação do primeiro curso formal, denominado de Primário, e diante da carência de docentes para atuarem naquela área rural em 1962 o Governo autoriza o funcionamento do Curso Normal/Regional, capacitando pessoas do campo para o exercício do Magistério Primário.

Até meados de 1950 as políticas implementadas pelo Governo Estadual para a Formação Docente no município surgiram a partir do ensejo dos habitantes em formar docentes para atuarem na sede do município e nas demais localidades vizinhas, pois era evidente a carência de profissionais formados na cidade para o exercício da atividade docente.

É notória a importância da Escola São José neste processo de formação docente no meio rural em Santarém, assim como merece destaque a iniciativa das ordens religiosas neste desafio. Cumpre frisar que, em virtude da histórica negligência estatal para com o campo, os cursos de formação docente ofertados nesta instituição proporcionaram uma qualificação relevante para que as comunidades atendidas desenvolvessem papel de protagonistas no processo de escolarização no campo na região. 
A presença do Governo do Estado no que se refere à questão da formação docente intensificou-se somente após a segunda metade do século XX, quando criou o Colégio Álvaro Adolfo, fundado no ano de 1962, pioneiro na Formação de Professores na cidade de Santarém. Tal iniciativa objetivava amenizar a carência de pessoal com formação mínima para atuar na área educacional e proporcionar formação complementar para docentes em exercício a exemplo dos cursos de Estudos Adicionais.

O currículo dos cursos ofertados em Santarém possuía características equivalentes as dos cursos oferecidos em outros estados. Na década de 1960 o curso pedagógico trabalhava disciplinas teóricas e não contemplava matérias que proporcionassem a prática docente, assim como apontam os estudos de Tanuri (2000).

O Plano Curricular do Curso Pedagógico ofertado no Colégio Álvaro Adolfo no final da década de 1960 apresentava áreas de conhecimentos denominados de Cultura Geral e Cultura Específica, no entanto as disciplinas específicas não passavam de atividades teóricas, de conhecimentos pedagógicos, técnicos.

Na década de 1970 algumas alterações curriculares são notadas. O Colégio Santa Clara ofertou o Curso Pedagógico no período de 1971 a 1978, assim como passou a ofertar o Curso Magistério em 1978. O currículo do Curso Pedagógico contemplava atividades de estágios denominados de Observação, Participação e de Direção, o que se diferenciava do currículo da década de 1960.

Os estágios de participação e direção contemplavam o momento decisivo para a formação, pois neste o futuro professor faria o encontro do teórico com o prático do Curso, proporcionando ao futuro professor a experiência e o contexto da complexidade da profissão docente. É importante ressaltar que a carga horária para cada estágio era de somente 40 horas por ano.

Com a oferta do Curso Magistério a partir de 1978 a nomenclatura do estágio modificou para Estágio Supervisionado, ainda ofertado nos dias atuais nos Cursos Superiores de Formação de Professores. Este estágio era realizado somente na $2^{\mathrm{a}}$ e $3^{\mathrm{a}}$ série do referido curso, no entanto proporcionava uma carga horária de 90 horas de estágio prático na $2^{\mathrm{a}}$ série, além de 180 horas na $3^{\mathrm{a}}$ série, proporcionando ao futuro professor uma experiência prática mais intensa no processo de formação inicial.

No Colégio Álvaro Adolfo, instituição assistida pelo Governo Estadual, na década de 1970 o currículo do Curso Colegial Normal não contemplava atividades práticas, somente disciplinas teóricas, sendo entendida como uma formação que proporcionava conhecimentos técnicos. Diante dessa problemática o Governo instituiu na década de 1980 os Estudos Adicionais, capacitação que tornava o técnico formado pelo Curso Colegial Normal em licenciado.

A partir da década de 1990 observou-se que o currículo do Curso Magistério havia avançado no sentido de contemplar disciplinas de Fundamentos da Educação, além de matérias didáticas, no qual os futuros professores estudavam a Metodologia de cada uma das ciências, além de colocarem em prática o que aprenderam no Estágio Supervisionado.

\section{CONSIDERAÇÕES FINAIS}

No decorrer do presente estudo podemos constatar que a qualificação de professores para as séries iniciais sempre foi relegada a segundo plano pelas políticas públicas educacionais. $\mathrm{O}$ Estado do Pará acompanhou esse descaso com a formação de professores, convivendo ainda hoje com a presença de professores leigos. A presença de professor sem a formação exigida em lei se deve a vários fatores, entre eles a baixa procura pelos cursos de licenciatura, a falta de valorização profissional, os salários pouco atrativos, a falta de realização de concursos públicos, entre outros. 
A questão parece não considerar que o município é um dos pioneiros, no estado em instituições escolares de formação de professoras tanto na rede pública quanto na privada e que, portanto necessita de estudos em que se possa servir a partir da trajetória dessas instituições, de referências de formação a gerações futuras.

Este estudo identificou estreita ligação entre a política nacional de expansão da formação de professores e a sua relação com a ampliação destes cursos em Santarém. Observou-se ainda que a política de fixação das instituições de ensino em Santarém considerou o crescimento populacional, o apoio do Estado e a força política da Igreja Católica (COLARES, 2005).

Conclui-se apontando a necessidade de ampliação das vagas nos cursos de formação docente em nível superior em Santarém, via programas especiais como o PARFOR por exemplo, e/ou outros que visem diminuir as carências de professores qualificados e oportunize uma ampliação qualitativa dos índices educacionais no município. Assim como, o desenvolvimento de plano de valorização da carreira do magistério, que valorize efetivamente o papel do professor.

\section{Referências}

ABNT. Associação Brasileira de Normas Técnicas. $3^{\text {a }}$ edição - Rio de Janeiro - 2011.

ALMEIDA, Critóvão Domingos de; GUINDANI, Joel Felipe e SÁ-SILVA, Jackson Ronie. Pesquisa documental: pistas teóricas e metodológicas. Revista Brasileira de História \& Ciências Sociais, Ano I-Número I- Julho de 2009.

. Lei de Diretrizes e Bases da Educação Nacional, Lei nº 5.692, de 11 de Agosto de 1971. Brasília - DF.

BRASIL. MEC. Lei de Diretrizes e Bases da Educação Nacional, Lei nº 9.394 de 20 de dezembro de 1996. Brasília - DF.

BRASIL. MEC. Plano Nacional de Educação. Brasília - DF.

COLARES, Anselmo Alencar. A história da educação em Santarém: das origens ao fim do Regime Militar (1661-1985). Santarém - Instituto Cultural Boanerges Sena 2005.

COLARES, M. L. I. S. Panorama da Educação em Santarém. Revista HISTEDBR on line. Campinas - São Paulo, n.23. p. 95-113, set 2006.

COWEN, Robert e FIGUEREDO, Maria C.M. Modelos de cursos de formação de professores e mudanças em políticas: um estudo sobre o Brasil. Disponível em http://www.schwartzman.org.br/simon/desafios/6professores.pdf. Acessado em 06/05/11, às $16: 22 \mathrm{~h}$.

FIGUEREDO, Nébia Maria Almeida. Método e metodologia na pesquisa científica. $3^{\mathrm{a}}$ Edição, São Caetano do Sul - São Paulo: Yendis Editora, 2008.

FONSECA, Wilde Dias da. SANTARÉM: Momentos Históricos. $4^{a}$ edição, Gráfica e Editora Tiagão, Santarém - 1996.

FRANCISCO FILHO, Geraldo. A Educação Brasileira no Contexto Histórico. Campinas São Paulo, editora Alínea, 2a edição, 2004.

PILETTI, Nelson. História da Educação no Brasil. Alínea Editora, 2ª edição, Campinas São Paulo, 2004. 
RANGHETTI, Diva Spezia. Políticas de formação inicial dos professores no Brasil: dos Jesuítas às Diretrizes da Pedagogia. Revista @ mbienteeducação, v. 1, nº1-Janeiro a Julho de 2008 - São Paulo.

SAVIANI, Demerval. Formação de professores: aspectos históricos e teóricos do problema no contexto brasileiro. Revista Brasileira de Educação, v.14, nº 40Campinas-São Paulo, 2009.

TANURI, Leonor Maria. História da Formação de Professores. Revista Brasileira de Educação, nº14, São Paulo, 2000.

VICENTINI, Paula Perin e LUGLI, Rosario Genta. História da profissão docente no Brasil: representações em disputa. São Paulo: Cortez, 2009.

VIEIRA, Alboni Marisa Dudeque Pianovski e GOMIDE, Angela Galizzi Vieira. História da formação de professores no Brasil: O primado das influências externas. Disponível em http:// www.pucpr.br/eventos/educere2008/anais/pdf/93_159. Acessado em 06/05/2011, às 16:07 h.

ZOTTI, Solange Aparecida. Organização do Ensino Primário no Brasil: Uma leitura da História do Currículo Oficial. Acessado em 17 de junho de 2011. Disponível em http://www.histedbr.fae.unicamp.br/navegando/artigos_frames/artigo_102.html.

Recebido: mai/15 Aprovado: jun/15 